\title{
Islanded microgrid congestion control by load prioritization and shedding using $\mathrm{ABC}$ algorithm
}

\author{
L. O. Mogaka ${ }^{1}$ G. N. Nyakoe ${ }^{2}$ M. J. Saulo ${ }^{3}$ \\ ${ }^{1}$ Department of Electrical and Electrinics Engineering, Pan African University Institute for Basic Sciences, \\ Technology and Innovation (PAUSTI), Kenya \\ ${ }^{2}$ Department of Electrical Engineering, Jomo Kenyattan University of Agriculture and Technology, Kenya \\ ${ }^{3}$ Department of Electrical Engineering, Technical University of Mombasa, Kenya
}

\begin{tabular}{l}
\hline \hline Article Info \\
\hline Article history: \\
Received Feb 15, 2019 \\
Revised Mar 23, 2020 \\
Accepted Apr 3, 2020
\end{tabular}

Keywords:

$\mathrm{ABC}$ algorithm

Congestion control

Islanding

Load shedding

Power losses reduction

Renewable energy sources

\begin{abstract}
The continued growth in load demand and the gradual change of generation sources to smaller distributed plants utilizing renewable energy sources (RESs), which supply power intermittently, is likely to strain existing power systems and cause congestion. Congestion management still remains a challenging issue in open access transmission and distribution systems. Conventionally, this is achieved by load shedding and generator rescheduling. In this study, the control of the system congestion on an islanded micro grid (MG) supplied by RESs is analyzed using artificial bee colony (ABC) algorithm. Different buses are assigned priority indices which forms the basis of the determination of which loads and what amount of load to shed at any particular time during islanding mode operation. This is to ensure as minimal load as possible is shed during a contingency that leads to loss of mains and ensure a congestion free microgrid operation. This is tested and verified on a modified IEEE 30-bus distribution systems on MATLAB platform. The results are compared with other algorithms to prove the applicability of this approach.
\end{abstract}

Copyright $@ 2020$ Institute of Advanced Engineering and Science. All rights reserved.

\section{Corresponding Author:}

L. O. Mogaka,

Department of Electrical and Electronics Engineering,

Pan African University Institute for Basic Sciences, Technology and Innovation (PAUSTI),

P. O. Box 62000-00200, Nairobi, Kenya.

Email: Mogaka.Lucas@gmail.com

\section{INTRODUCTION}

The electrical power market deregulation and the gradual evolution of the grids towards smart grid (SG) is currently being witnessed in an effort to supply power to the increasing population and flourishing industries. The RESs in the SGs are expected to be more resilient with the ability to survive system difficulties during contingencies $[1,2]$. However, this change from conventional monopolistic system to deregulated system may make the system to operate beyond its voltage and thermal limits hence transmission and distribution system congestion [3]. Congestion can be defined as difference in the scheduled and the actual power flow in a given line without violating the set limits [4]. It is a condition where more power is scheduled to flow across transmission, distribution lines and transformers than what those lines can carry [5]. Operation in islanded mode is recommended in order to prevent total blackouts in the power system [6]. This ensures power is supplied to customers reliably in a safe way and maintains the system security.

The methods used for congestion management (CM) can be classified into two; Cost free and noncost-free methods [7]. The cost-free method includes use of FACTS devices, outaging congested lines, and the operation of transformer taps. On the other hand, the non-cost-free methods include shedding of some loads, generator rescheduling among others. The increase in competitive pressure in the electrical power industry necessitates removal of overloads through load shedding bearing in mind the economic and the cost 
of shedding the load [8]. In addition to the above conventional methods, evolutionary algorithms like $\mathrm{ABC}$, particle swarm optimization (PSO), ant colony optimization (ACO), cuckoo search algorithm (CS), harmony search algorithm (HS), shuffled frog leaping algorithm (SFLP), simulated annealing algorithms (SA) among others are also increasingly being used in CM [9-11].

A number of studies on CM have been done so far. For instance, reference [12] proposes two measures that can be used to control congestion; generator rescheduling and loss reduction of real power. In [13], the author proposes the use of FACTS devices in the management of congestion at transmission level. In [14], rescheduling of sensitive generators and load shedding is proposed for CM using PSO algorithm. In [15], the author used the sensitivities of overloaded lines together with the cost of power generation and load shedding in CM. The load-shedding schedule and new power generation for affected buses was calculated using line sensitivities and the cost.

It is challenging to control the power produced in an islanded MG by RESs because these sources produce power intermittently. Load shedding is the main method of controlling system stability in this case and avoid any danger within the MG [16]. Optimal shedding of connected loads assists in reducing the difference between the power that DGs can supply and the connected loads [17]. In [18], ABC algorithm is used for overload control by rescheduling generators. The author uses generator sensitivity factors in selecting the generators that participate in real power rescheduling. In [19], ABC and PSO algorithms were used in generator rescheduling based on bus and generator sensitivity factors for CM in a system with wind energy resources only. In [20], the authors used PSO in generation rescheduling and load shedding in CM. In [21], congestion alleviation in a deregulated power system is proposed using cuckoo search algorithm. This was tested on IEEE 30-bus system. A modification of ABC algorithm is applied in the determination of the DG power output and their location in reference [22]. This was tested on 33 bus system.

Through load shedding, the amount of power demand that can be curtailed so as to mitigate CM problem is determined. From the literature, extensive research on CM on MGs has been done. However, CM using load shedding algorithms still remains an open issue and needs further research. In this paper, the CM problem in an islanded MG supplied with RESs is analyzed. This is formulated as an optimization problem. ABC algorithm is used in the determination of the optimal amount of load to be shed and from which buses based on their priority index. This rest of this paper is organized as follows; section 2 discusses the proposed congestion management method, its mathematical formulation and how ABC algorithm will be applied; section 3 analysis the simulation results and 4 summarizes and concludes this paper.

\section{PROPOSED CM SCHEME IN AN ISLAND WITH RESS}

This simulation assumes that MG is suddenly switched to island operation mode due to a contingency that leads to loss of mains. After a utility grid disturbance that lead to islanding mode, the power in the MG is allocated to the loads as per their priority index. Figure 1 below is a sketch of a MG with RESs that was used for CM analysis in this study. The loads and buses within the islanded MG were given priority indices, and then $\mathrm{ABC}$ algorithm was modified and applied in shedding loads in order to ensure the system is not stretched beyond its limits. Figure 2 is the proposed load shedding power flow for this study.

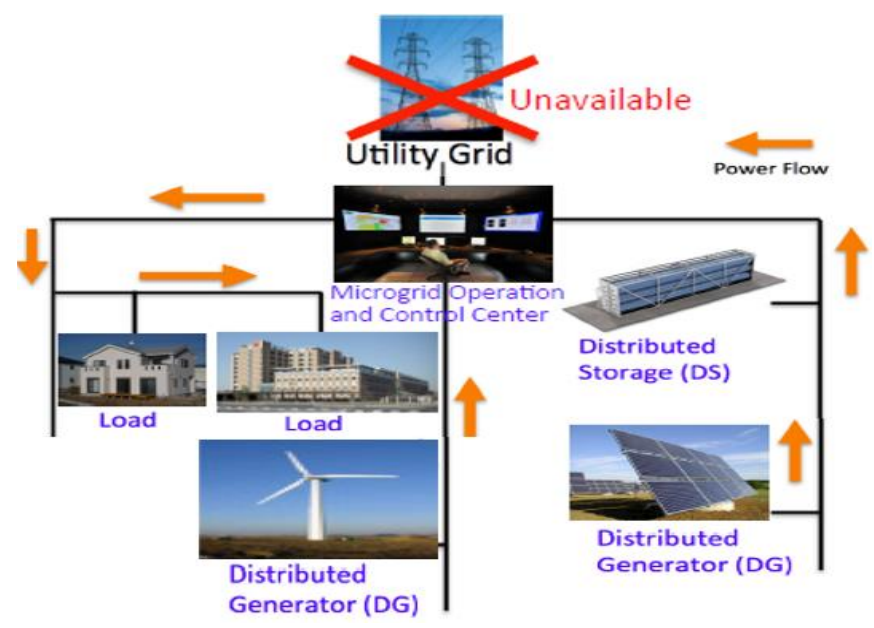

Figure 1. Micro grid with RESs 


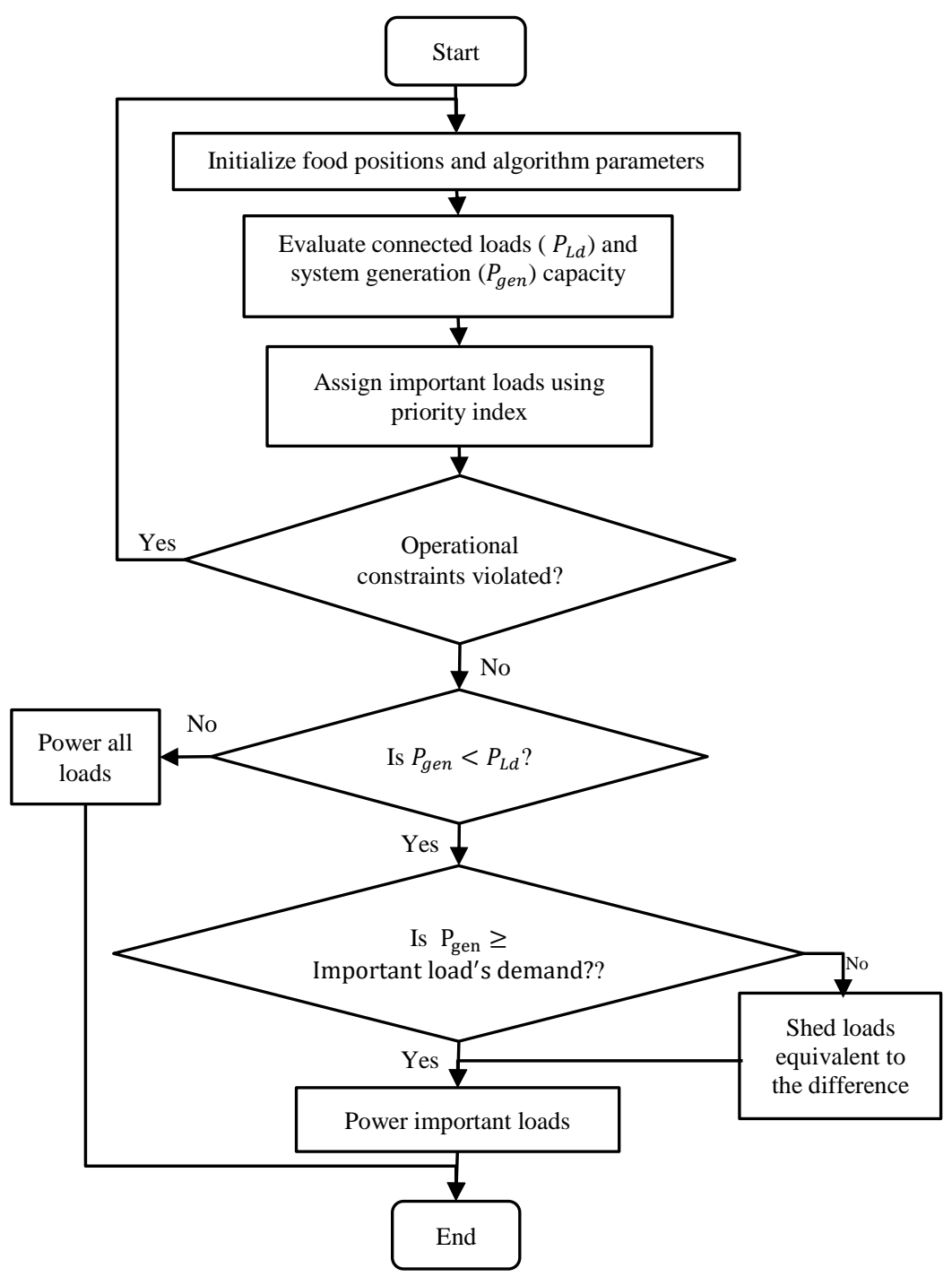

Figure 2. Load shedding power flow for CM

\subsection{Mathematical problem formulation}

The main objective of this paper is to alleviate elements of system congestion in an islanded MG through minimizing overloads by optimal load shedding using $\mathrm{ABC}$ algorithm. This is expressed the expressions 1-3 below;

$$
\begin{aligned}
\text { Minimize } F_{1}= & \sum_{i=1}^{O L}\left(S_{i}-S_{i}^{\max }\right)^{2} \\
\text { Minimize } F_{2}= & \sum_{i=1}^{N G}\left(P_{i}+Q_{i} P_{g i}+R_{i} P_{g i}^{2}\right)+\left|e_{i} * \sin \left(f_{i} *\left(P_{g i}-P_{\min , i}\right)\right)\right| \\
& +\sum_{k=1}^{P L}\left(P_{k}^{\prime}+Q_{k}^{\prime} L_{s h d, k}\right)
\end{aligned}
$$

$$
\text { Minimize } P_{l}=F\left(P_{g, \text { slack }}\right)
$$


where $P_{l}$ is the system real power loss, $S_{i}^{\max }$ is the maximum capacity of line $i, O L$ is the number of the lines that are overloaded,$L_{s h d, k}$ is the amount of load to be shedded at bus $\mathrm{k}, P_{g i}$ is the power generated by generator $i, S_{i}$ is the power flow on line $i, N G$ is the number of participating generators, $P_{\min , i}$ is the minimum power generated by generator $i, f_{i}$ and $e_{i}$ are the generator coefficients for generator.

Subject to the equality and inequality constraints (4-10) below:

Equality constraints,

$$
\begin{aligned}
& P_{g i}-P_{d i}=\sum_{j=1}^{N B}\left|V_{i}\right|\left|V_{j}\right|\left|Y_{i j}\right| \cos \left(\delta_{i}-\delta_{j}-\theta_{i j}\right) \\
& Q_{g i}-Q_{d i}=\sum_{j=1}^{N B}\left|V_{i}\right|\left|V_{j}\right|\left|Y_{i j}\right| \sin \left(\delta_{i}-\delta_{j}-\theta_{i j}\right)
\end{aligned}
$$

where $\left|V_{i}\right|$ and $\left|V_{j}\right|$ are voltage magnitudes.

The distributed generation RESs constraints

$$
\begin{aligned}
& P_{g i}^{\min } \leq P_{g i} \leq P_{g i}^{\max } \\
& Q_{g i}^{\min } \leq Q_{g i} \leq Q_{g i}^{\max }
\end{aligned}
$$

where $P_{g i}^{\min }$ and $P_{g i}^{\max }$ are Real power generation limits of the RES $i$ and $Q_{g i}$ is the VAR generated by RES $i$ Voltage constraint

$$
\begin{aligned}
& V_{g i}^{\min } \leq V_{g i} \leq V_{g i}^{\max } \\
& V_{d i}^{\min } \leq V_{d i} \leq V_{d i}^{\max }
\end{aligned}
$$

where $V_{g i}$ and $V_{d i}$ is voltage magnitude at generator and load bus $i$ respectively.

$$
\sum_{i=1}^{N G} P_{g i}=\sum_{k=1}^{N D} P_{d k}+P_{l}
$$

where $P_{d k}$ is the real power load at bus $\mathrm{k}, N G$ and $N D$ are the sets of generator and load buses respectively.

\section{2. $\mathrm{ABC}$ algorithm}

Swarm intelligence algorithms are the currently preferred approaches in solving dynamic optimizationNP-hard problems in engineering [23]. ABC algorithm is a meta-heuristic optimization algorithm that was proposed by Karaboga from Erciyes University of Turkey [24]. This algorithm mimics the foraging movement of a swarm of bees in search of nectar around the hive as shown in Figure 3 [22]. In this algorithm, the location of food sources represents a possible solution to an optimization problem being solved. The quantity and quality of nectar indicates the fitness of that particular solution.

It has a superior performance in solving engineering problems when compared to other algorithms. For instance, it can handle both continuous and discrete variables. It is mostly applied to optimization problems in power systems that are not smooth. It is divided into three groups as observed from the behavior of a swarm of bees where each group performs a particular function as highlighted below [25];

- The employed bees. They are equal to the possible solutions of the problem. This group continuously updates the rest of the bees in the hive about the quantity, quality and the direction of the food source through the performance of a waggle dance. The duration of the waggle dance depends on the quality and quantity of food source.

- The onlooker group of bees. These bees pick on a food source to exploit based on the information provided by the employed bees waggle dance. More onlookers move to food sources with high fitness and few to food sources with lesser fitness values.

- The scout bees. These bees work is to look for new sources of food for exploitation. They randomly choose food sources around the hive. 


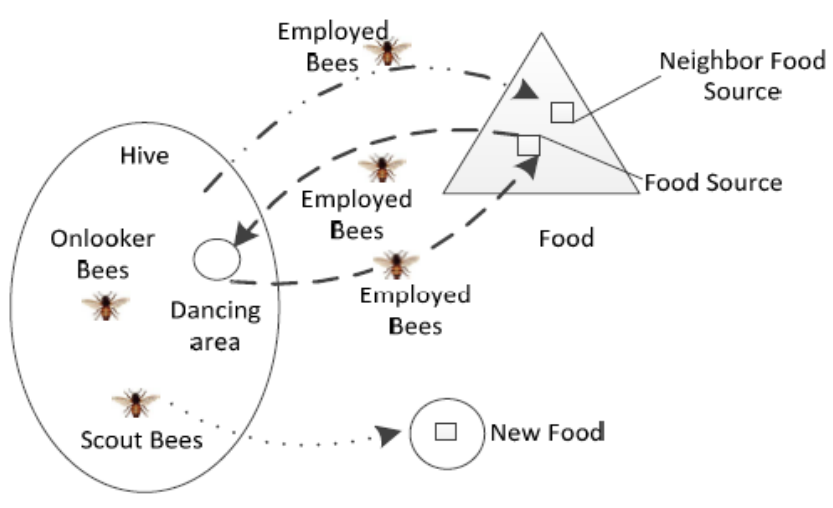

Figure 3. ABC search behavior

\section{3. $\mathrm{ABC}$ algorithm steps}

The initial phase where random population is generated. The solution size is taken to be equal to the number of employed bees. Each of the above solution is a vector of dimension $D$. This dimensional vector $\mathrm{D}$ corresponds with the number of parameters being optimized. The fitness (quality) of a food source can be expressed by (11):

$$
\text { fitness }_{i}=\frac{1}{1+f_{i}}
$$

where objective function $f_{i}$ is the problem formulation target.

The above generated initial population of possible solutions is then sequentially subjected through the three categories of bees in cycles till the specified maximum cycle number (MCN) is reached. Employed bees keeps on modifying the memories of the food locations (solutions) based on the visual observations and nectar quality. The employed bees share the food source information with the rest of the bees in the hive through waggle dance.

The onlooker bee will choose a preferred food source based on the amount of nectar available and as per the probability guided by the equation below [26];

$$
p_{i}=\frac{\text { fitness }_{i}}{\sum_{j=1}^{t s} \text { Fitness }_{j}}
$$

where $t s$ is the number of employed bees (= number of the sources of food) and fitness $s_{i}$ is the fitness value of the $i^{\text {th }}$ solution.

The onlooker bee then compares the food sources from the information given by employed bees and then chooses a neighbor food source if it is better than the current one using the following equation;

$$
X_{i j}^{\text {new }}=X_{i j}^{\text {old }}+Q_{i j}\left(X_{i j}^{\text {old }}-X_{k j}\right)
$$

where $Q_{i, j}$ is a random number that lies between -1 and $1, X_{k, j}$ is the neighbouring food source that can be randomly selected and $X_{i j}^{\text {old }}$ and $X_{i j}^{\text {new }}$ are old and new food sources respectively.

If the food source does not improve after a number of trials, it is abandoned and the associated bee becomes a scout. These steps are continuously repeated until the maximum cycle or stopping criteria is met. Then, the food with the highest fitness value is selected and printed.

\section{RESULTS AND DISCUSSIONS}

IEEE 30-bus is used to test applicability of this approach in congestion management. This system has a total of six generators, 41 lines, 24 load buses and 21 loads. It has a total of $283.400 \mathrm{MW}$ active and 126.200 MVAR reactive loads connected to the system. This is shown in Figure 4. The simulation was carried out on MATLAB/SIMULINK platform on an AMD 4C+6G $2.10 \mathrm{GHz}$ processor with 4GB RAM. The control parameters for ABC algorithm were set as shown in the Table 1. 


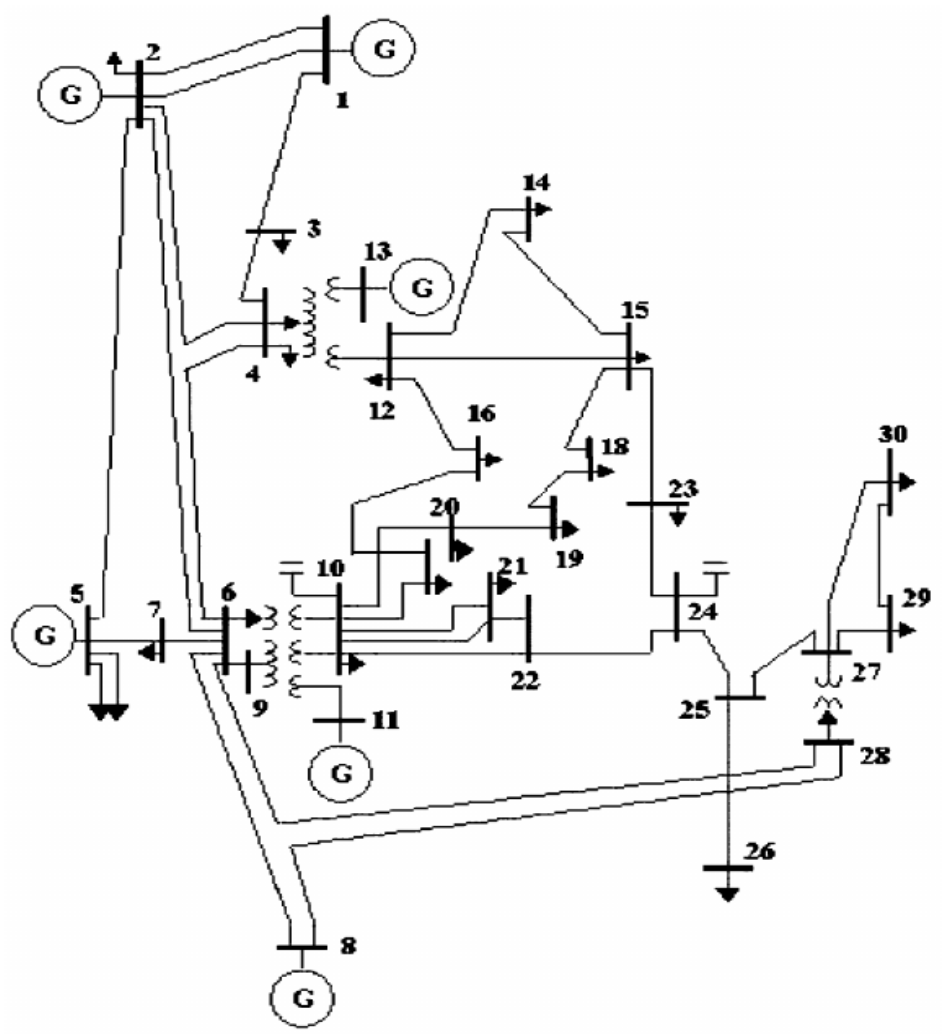

Figure 4. IEEE standard 30 bus system

Table 1. ABC parameter settings

\begin{tabular}{clc}
\hline S/N & \multicolumn{1}{c}{ Parameter } & Value \\
\hline 1 & Colony size & 40 \\
2 & Employed bees & 20 \\
3 & Limit value & 100 \\
4 & Number of onlooker bees & 20 \\
5 & MCN & 100 \\
\hline
\end{tabular}

Two test cases were simulated and Newton Raphson power flow run to test the congestion status in the island. The test cases done are shown in Table 2. In this case, congestion is simulated by creating an outage on lines 1-2 and 1-7 and overloading the lines.

Table 2. Test cases description

\begin{tabular}{cl}
\hline Test case & \multicolumn{1}{c}{ Contingency Description } \\
\hline 1 & Outage of line 1-2 \\
2 & Outage of line 1-7 with increase in load at all buses by $50 \%$ \\
\hline
\end{tabular}

\subsection{Case 1}

The outage of line 1-2 brings congestion between lines 1-7 and 7-8 of the modified system. The total system loss increases to 16.069 MW from 7.376 MW. This is compared with the CM using firefly algorithm as shown in the Table 3.

Table 3. Total system loss for case 1

\begin{tabular}{lll}
\hline & MW & MVar \\
\hline Normal condition & 7.376 & -15.043 \\
Outage of line 1-2 contingency & 16.069 & 21.303 \\
After load shedding (20.552MW) using ABC algorithm & 11.649 & 4.305 \\
Using Firefly algorithm & 13.10 & Not given \\
\hline
\end{tabular}


From the load flow, the power flowing between the two congested lines becomes 147.509 and 136.348 MW respectively against the set limit of 130MW. This condition is alleviated by shedding 20.552 MW load from the buses with least priority indices using ABC algorithm. After load shedding, the power flow between the two congested lines comes down to 122.537 MW and 114.093 MW which is well within the limit. This is as shown in Table 4. The Figure 5 shows the voltage profiles at various buses for normal, during the fault and after load shedding using $\mathrm{ABC}$ algorithm. There is a great improvement in the voltage profiles on the system buses after load shedding.

Table 4. Power flow for case 1

\begin{tabular}{llll}
\hline Congested line & Actual power flow (MW) & Power flow after load shedding using ABC & Line limit (MW) \\
\hline $1-7$ & 147.348 & 122.537 & 130 \\
$7-8$ & 136.348 & 114.093 & 130 \\
\hline
\end{tabular}

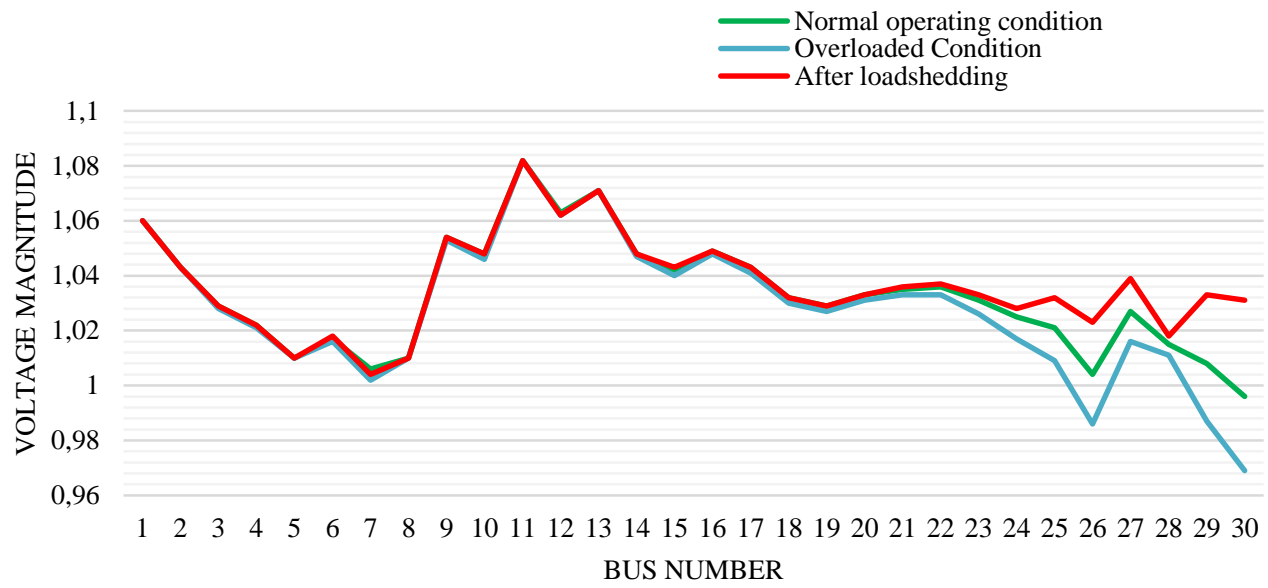

Figure 5. Voltage profile for test case 1

\subsection{Case 2}

In this section, the system loads were increased by $50 \%$ and then line 1-7 outaged. This caused congestion on lines 1-2, 2-8 and 2-9 of 313.914MW, 98.411MW and 104.769 MW respectively against the set limits of 130MW for line 1-2 and 65MW for lines 2-8 and 2-9. In this study, the total power Flow violation on the lines due to congestion is $257.088 \mathrm{MW}$ while it is $251.794 \mathrm{MW}$ in the study by reference [4]. This is shown in the Table 5.

The system losses were also monitored during and after load shedding using $\mathrm{ABC}$ algorithm. Applying ABC algorithm, 41.268 MW was shed to mitigate congestion levels. The total losses were recorded as shown in Table 6. The total losses decreased from 38.164 during the contingency to $17.485 \mathrm{MW}$ after load shedding. This is compared by the congestion management approach using firefly algorithm in reference [4]. As can be observed from the figure, the total power losses for the two approaches is almost the same. This is elaborated in Figure 6.

Table 5. Congested lines for case 2

\begin{tabular}{ccc}
\hline Congested line & Actual power flow (MW) & Line limit (MW) \\
\hline $1-2$ & 313.914 & 130 \\
$2-8$ & 98.411 & 65 \\
$2-9$ & 104.769 & 65 \\
\hline
\end{tabular}

Table 6. Total losses for case 2

\begin{tabular}{lll}
\hline & MW & MVar \\
\hline Normal condition & 7.376 & -15.043 \\
Outage of line 1-7 and 50\% load increase & 38.164 & 97.773 \\
After load shedding (41.268MW) using ABC algorithm & 26.770 & 54.706 \\
\hline
\end{tabular}




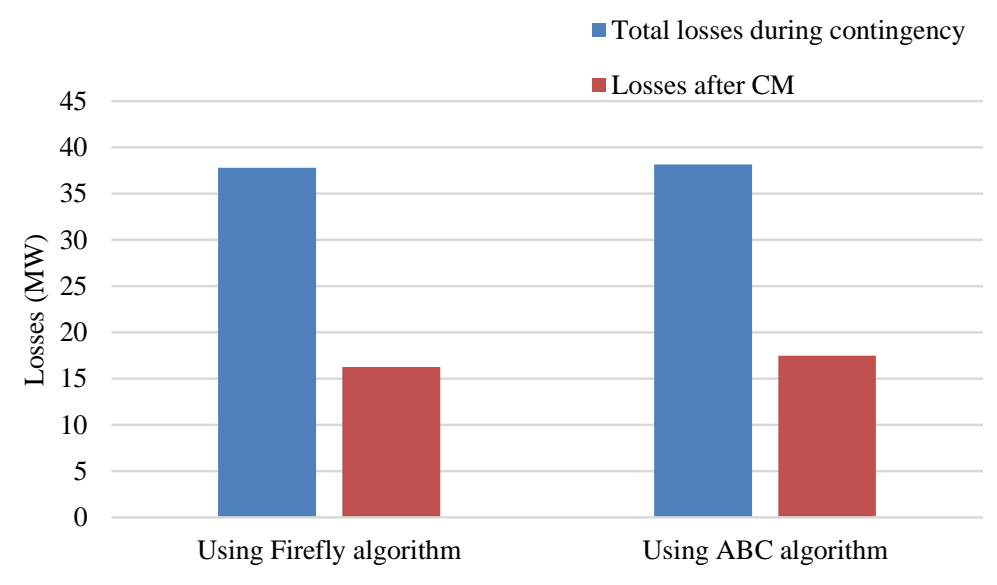

Figure 6. System losses comparison for case 2

The CM by load shedding using ABC algorithm was compared with CM by generator rescheduling using FFA, PSO, RSM and SA as reported in [4]. The power flows comparison is as shown in Table 7. The voltage profiles before, during the contingency and after $\mathrm{CM}$ by load shedding using ABC algorithm were monitored. The $\mathrm{CM}$ by load shedding using $\mathrm{ABC}$ algorithm improves the voltage profiles within the islanded MG. This is shown in Figure 7.

Table 7. Comparison of various algorithms in CM

\begin{tabular}{llllll}
\hline Power flow (MW) & FFA & PSO & RSM & SA & ABC \\
\hline Line 1-2 & 130 & 129.7 & 129.91 & 129.78 & 204.225 \\
Line 2-8 & 62.713 & 61.1 & 52.36 & 51.47 & 59.509 \\
Line 2-9 & 64.979 & 64.67 & 55.43 & 54.04 & 63.396 \\
\hline
\end{tabular}

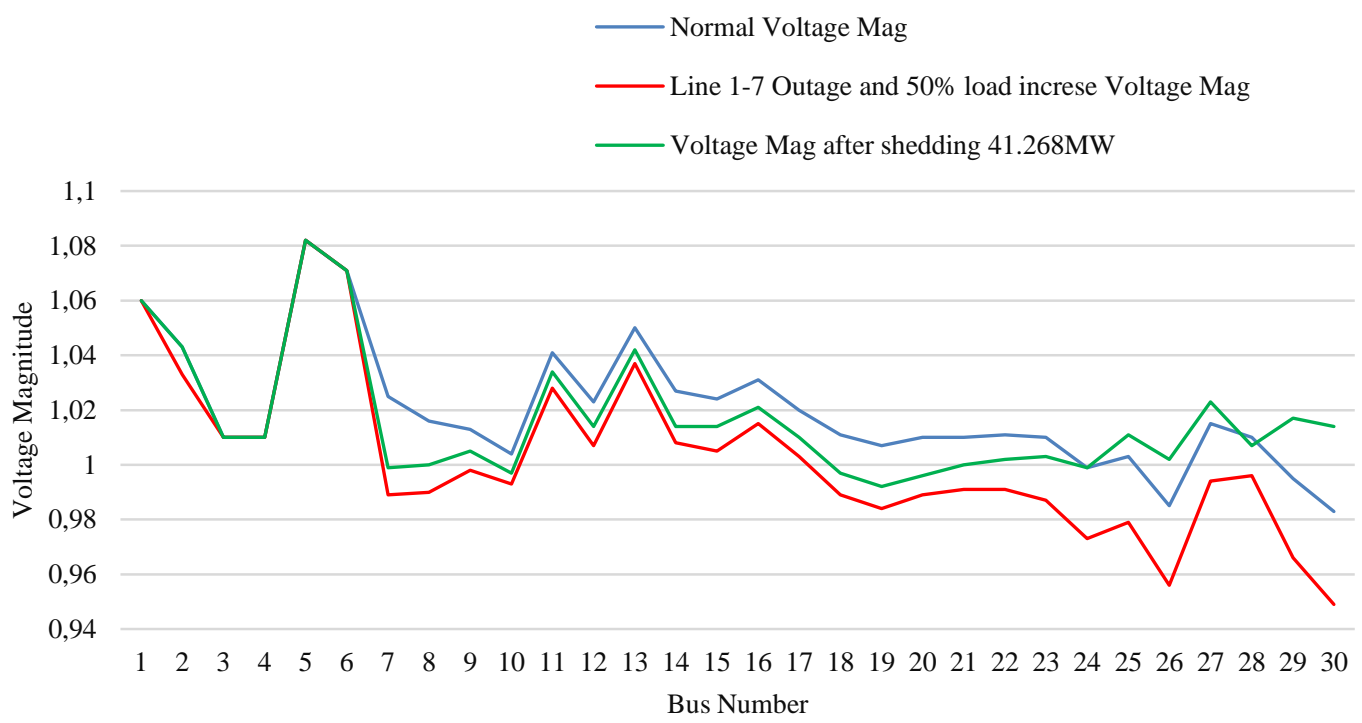

Figure 7. Voltage profiles for case 2

Convergence characteristics for this case was also monitored before the contingency, during the contingency and after load shedding. The iteration converged 14 iterations before the contingency, after 35 iterations during the contingency and converged after 29 iterations after load shedding. This is shown in the Figure 8. 


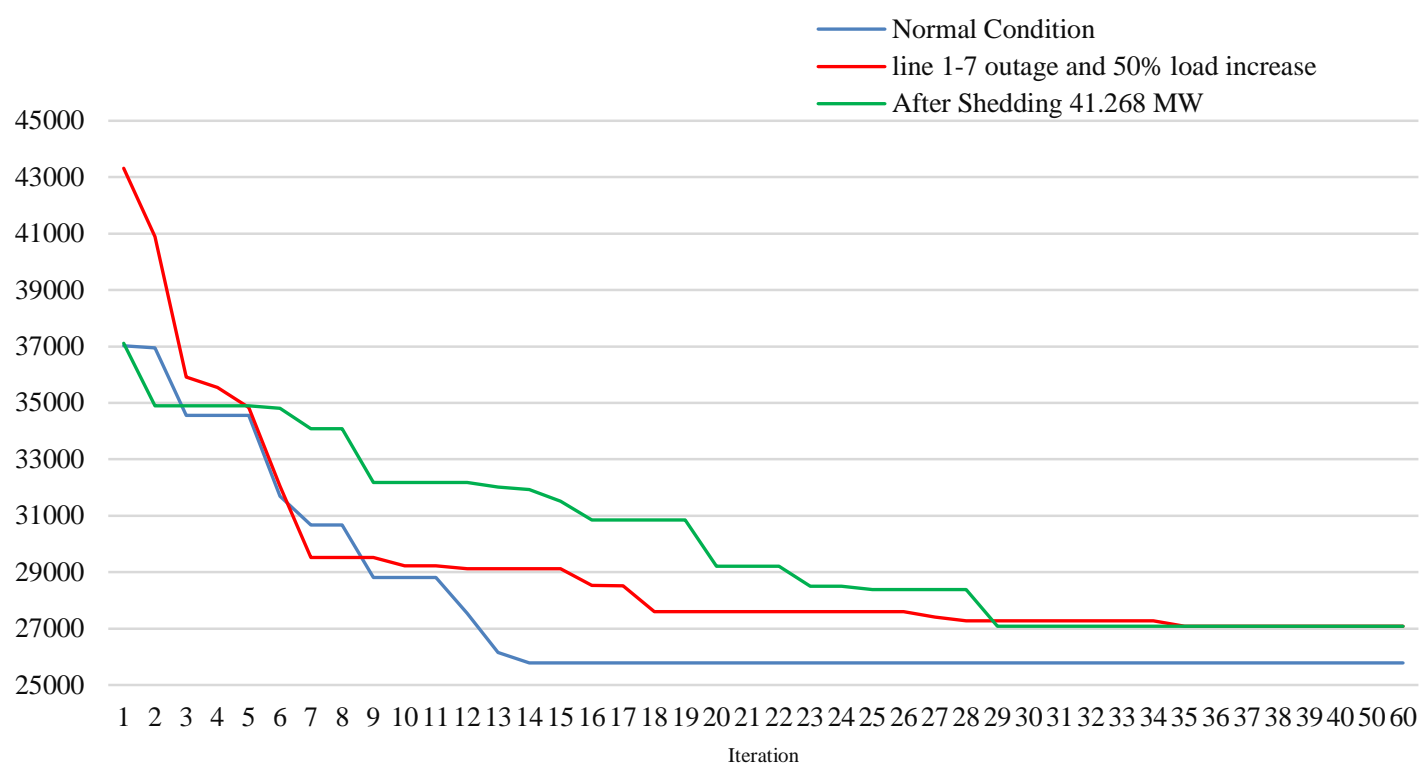

Figure 8. Convergence characteristics

\section{CONCLUSION}

This paper has presented an approach for congestion management on an islanded MG with RESs. Here, load shedding using ABC algorithm has been successifully employed for congestion management in an islanded microgrid. Various loads and buses were chosen for shedding based on their priority index to help mitigate the congestion problem. This was tested and validated on a modified IEEE 30 bus system with contingencies and sudden load increase in the micrgrid introduced. The results were compared with those from other algorithms like firefly algorithm and PSO as reported in the literature. The results show a great superiority of this approach over these algorithms. As it can be observed, this proposed method can greatly improve the system stability of the islanded MG through the minimization of the load shed and maintain the voltage profile within the required limits. This is due to superior convergence characteristics of ABC algorithm. This approach can therefore berecommeded in the solution of optimization problems in engineering and other fields as well.

\section{ACKNOWLEDGMENT}

This research was supported by the Pan African University Institute for Basic Sciences, Technology and Innovation in the form of a postgraduate student research funding.

\section{REFERENCES}

[1] K. Takumi, T. Hideyuki, S. Kazuto, K. Gen, K. Hak-Man and K. Tetsuo, "Priority-based hierarchical operational management for multiagent-based microgrids," Energies, vol. 7, pp. 2051-2078, 2014.

[2] D. Mohammad, M. Hazlie and M. Saad, "Application of Meta-heuristic techniques for optimal load shedding in islanded distribution network with high penetration of solar PV generation," Energies, vol. 10, no. 150, pp. 1-24, 2017.

[3] P. Oana, B. Constantin and K. Stefan, "Contingency-Constrained congestion management and transmission cost allocation," Acta Polytechnica Hungarica, vol. 11, no. 7, pp. 83-102, 2014.

[4] V. Sumit and V. Mukherjee, "Firefly algorithm for congestion management in deregulated environment," Engineering Science and Technology, an International Journal, vol. 19, pp. 1254-1265, 2016.

[5] K. Elango, S. R. Paranjothi and C. Sharmeela, "Transmission congestion management in restructured power systems by generation rescheduling and load shedding using rule based OPF," European Journal of Scientific Research, vol. 57, no. 2, pp. 380-390, 2011.

[6] M. M. K. Seyedeh and K. Amangaldi, "Local power controller based load shedding scheme in islanded microgrids," International Journal of Renewable Energy Research, vol. 9, no. 2, pp. 1108-1115, 2019

[7] S. Thangalakshmi and P. Valsalal, "Congestion management using hybrid fish bee optimization," Journal of Theoretical and Applied Information Technology, vol. 58, no. 2, pp. 1405-1412, 2013.

[8] J. Hazra, A. K. Sinha and Y. Phulpin, "Congestion management using generation rescheduling and/or load shedding of sensitive buses," Third International Conference on Power Systems, 2009. 
[9] G. Srinivasulu and P. Balakrishna, "A case study on analysis of congestion management methods in smart grid scenario," International Conference on Computing, Power and Communication Technologies, pp. 242-247, 2018.

[10] I. Y. Nurul, A. M. Z. Abdullah and B. K. Azhar, "Congestion management in power system: A review," 3rd International Conference on Power Generation Systems and Renewable Energy Technologies (PGSRET), 2017.

[11] S. Suganthi, K. Ramar, T. Hosimin and D. Devaraj, "A novel approach for congestion management using improved differential evolution algorithm," International Transaction on Electrical Energy System, pp. 1-19, 2018.

[12] S. Charlesraja and P. Venkatesh, "Transmission congestion management in restructured power system," Proceedings of ICETECT, pp. 23-28, 2011.

[13] M. Joorabian and M. Saniei, "Optimal locating and sizing of TCPST for Congestion management in Deregulated Electricity markets," UPEC, 46th International Universities' Power Engineering Conference, 2011.

[14] T. Bhattacharjee and A. K. Chakraborty, "Congestion management in a deregulated power system by rescheduling of sensitive generators and load curtailment using PSO," IJETAE, vol. 2, no. 3, pp. 284-289, 2012.

[15] B. K. Talukdar, A. K. Sinha, S. Mukhopadhyay and A. and Bose, "A computationally simplemethod for cost-efficient generation rescheduling and load shedding for congestion management," International Journal Electrical Power Energy System, vol. 27, no. 5, p. 379-388, 2005.

[16] C. Yeongho, L. Yujin and K. Hak-Man, "Optimal load shedding for maximizing satisfaction in an islanded microgrid," Energies, vol. 10, no. 45, pp. 1-13, 2017.

[17] S. Fatma and K. Salah, "Optimal load shedding for voltage collapse prevention using improved harmony search algorithm," Nineteenth International Middle East Power Systems Conference, 2017.

[18] R. Saranya, K. Balamurugan and M. Karuppasamypandiyan, "Artificial bee colony algorithm based congestion management in restructured power system," Indian Journal of Science and Technology, vol. 8, no. 7, pp. 171-178, 2015.

[19] R. Mageshvaran and T. Jayabarathi, "Steady state load shedding to prevent blackout in the power system using artificial bee colony algorithm," Jurnal Teknologi (Sciences \& Engineering), vol. 74, no. 1, pp. 113-124, 2015.

[20] T. Bhattacharjee and A. K. Chakraborty, "Congestion management in a deregulated power system by rescheduling of sensitive generators and load curtailment using PSO," IJETAE, vol. 2, no. 3, pp. 284-289, 2012.

[21] N. Chidambararaj and K. Chitra, "Congestion management based on active power rescheduling of generator units using cuckoo search algorithm," International Journal of Scientific \& Engineering Research, vol. 5, no. 4, pp. 33-38, 2014.

[22] N. B. M. Mohd and F. Goro, "Distribution network power loss by using artificial bee colony," IEEE, pp. 1-5, 2013.

[23] V. Z. Manusov, P. V. Matrenin and N. Khasanzoda, "Swarm algorithms in dynamic optimization problem of reactive power compensation units control," International Journal of Electrical and Computer Engineering (IJECE), vol. 9, no. 5, pp. 3967-3974, 2019.

[24] D. Karaboga, B. Gorkemli, C. Ozturk and and N. Karaboga, "A comprehensive survey: Artificial bee colony (ABC) algorithm and applications," Artificial Intelligence Reviews, vol. 42, pp. 21-57, 2012.

[25] K. M. Sagayam and D. J. Hemanth, "ABC algorithm based optimization of 1-D hidden Markov model for hand gesture recognition applications," Computers in Industry, vol. 99, pp. 313-323, 2018.

[26] B. Hamid, B. Bachir and R. Abdelhadi, "Analysis of the impact of metal thickness and geometric arameters on the quality factor-Q in integrated spiral inductors by means of artificial bee colony technique," International Journal of Electrical and Computer Engineering (IJECE), vol. 9, no. 4, pp. 2918-2931, 2019. 